\title{
Unraveling the Lattice Matching Effect in Surface Phase Junctions for Interfacial Charge Separation
}

Jifa Liu, ${ }^{1+t}$ Fangfang Wang, ${ }^{1 *}$ Xuebing Chen, ${ }^{1}$ Rengui Li, ${ }^{2}$ Peng Yan, ${ }^{1}$ Song Bai, ${ }^{1}$ Xia Yang, ${ }^{1}$ and Jing Zhang $^{1 *}$

${ }^{1}$ School of Environmental and Safety Engineering, Liaoning Petrochemical University, No.1 West Dandong Road, Wanghua District, Fushun 113001, Liaoning Province, China

${ }^{2}$ State Key Laboratory of Catalysis, Dalian National Laboratory for Clean Energy, Dalian Institute of Chemical Physics, Chinese Academy of Sciences, Zhongshan Road 457, Shahekou District, Dalian 116023, Liaoning Province, China

¥These authors contributed equally to this work.

\section{Corresponding Author}

*Email: jingzhang_dicp@live.cn 


\section{Table of Contents}

\begin{tabular}{|c|c|}
\hline & Captions \\
\hline Figure S1 & (a) XRD pattern and (b) TEM image of A sample. \\
\hline Figure S2 & (a) XRD pattern and (b) SEM image of R sample. \\
\hline Scheme S1 & $\begin{array}{l}\text { Schematic illustration of preparing } A / R \text { heterophase } \\
\text { junction and } R_{S} / R \text { homophase junction. }\end{array}$ \\
\hline Figure S3 & (a) XRD pattern and (b) Raman spectrum of $R_{s}$ sample. \\
\hline Figure S4 & SEM images of (a) A/R and (b) $R_{s} / R$ samples. \\
\hline Table S1 & The surface areas of $R, A / R$ and $R_{s} / R$ samples. \\
\hline Figure S5 & $\begin{array}{l}\text { UV-vis diffuse reflectance spectra of R, } 5 \% \mathrm{~A} / \mathrm{R} \text {, and } 5 \% \\
\mathrm{R}_{\mathrm{S}} / \mathrm{R} \text {. }\end{array}$ \\
\hline Figure S6 & $\begin{array}{l}\text { The overall photocatalytic } \mathrm{H}_{2} \text { evolution on } \mathrm{R} \text { and } 5 \% \mathrm{~A}+\mathrm{R} \\
\text { samples with methanol as scavenger, } 0.2 \mathrm{wt} \% \mathrm{Pt} \\
\text { photodeposited as cocatalyst and xenon lamp }(300 \mathrm{~W}) \text { used } \\
\text { as light source. }\end{array}$ \\
\hline Figure S7 & $\begin{array}{l}\text { The overall photocatalytic } \mathrm{H}_{2} \text { evolution on } \mathrm{R} \text { and } 5 \% \mathrm{R}_{\mathrm{s}}+\mathrm{R} \\
\text { samples with methanol as scavenger, } 0.2 \mathrm{wt} \% \mathrm{Pt} \\
\text { photodeposited as cocatalyst and xenon lamp }(300 \mathrm{~W}) \text { used } \\
\text { as light source. }\end{array}$ \\
\hline Figure S8 & $\begin{array}{l}\text { Comparison of photocatalytic overall water splitting } \\
\text { performance on } \mathrm{R}, 5 \% \mathrm{~A} / \mathrm{R} \text {, and } 5 \% \mathrm{R}_{\mathrm{S}} / \mathrm{R} \text { samples. }\end{array}$ \\
\hline Figure S9 & $\begin{array}{l}\text { UV-vis diffuse reflectance spectra (inset: the estimated band } \\
\text { gap of } A, R_{s} \text {, and } R \text { ). }\end{array}$ \\
\hline Figure S10 & $\begin{array}{l}\text { Schematic illustration of the band structures of (b) A and R, } \\
\text { (c) } R_{s} \text { and } R\end{array}$ \\
\hline Figure S11 & SPV responses of $\mathrm{R}$ and $\mathrm{A} / \mathrm{R}$ samples. \\
\hline
\end{tabular}




\section{Supplementary Figures}

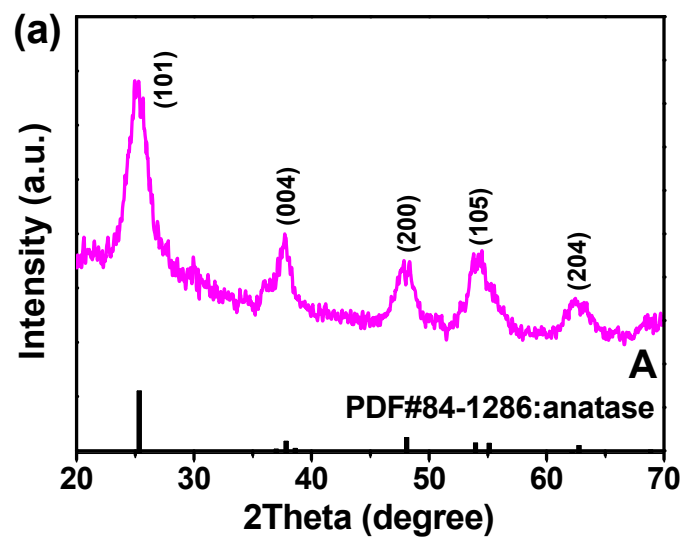

(b)

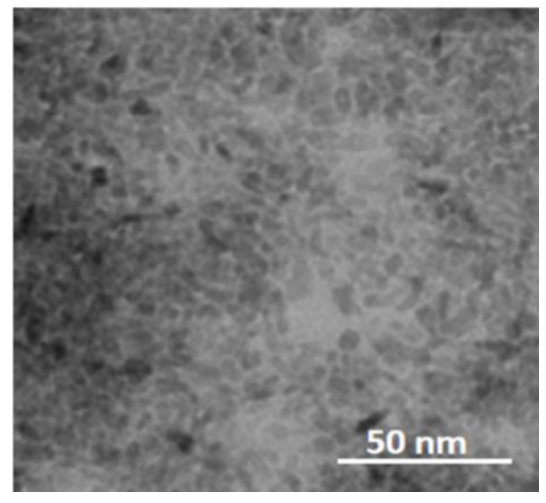

Figure S1. (a) XRD pattern and (b) TEM image of A sample. 


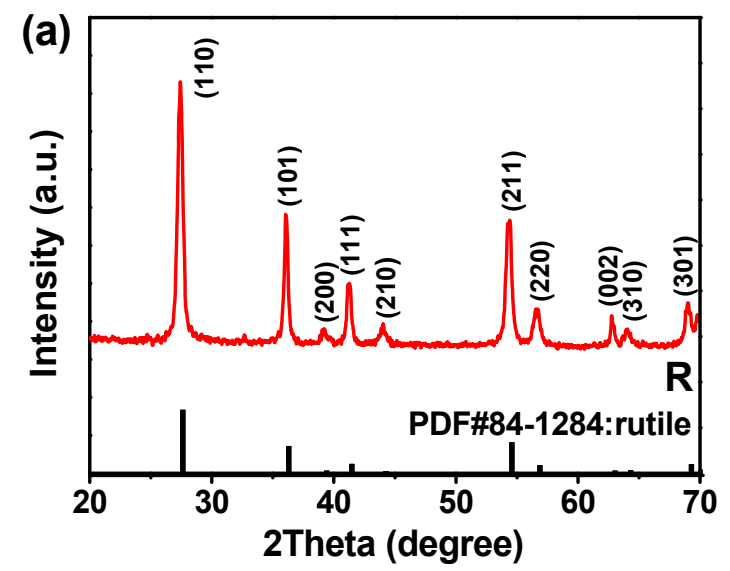

(b)

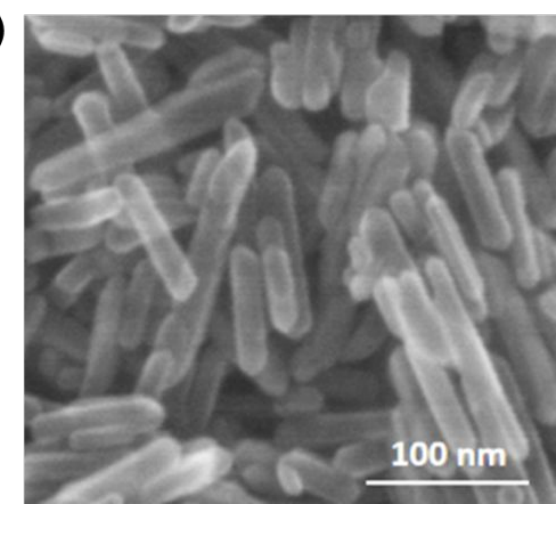

Figure S2. (a) XRD pattern and (b) SEM image of R sample. 


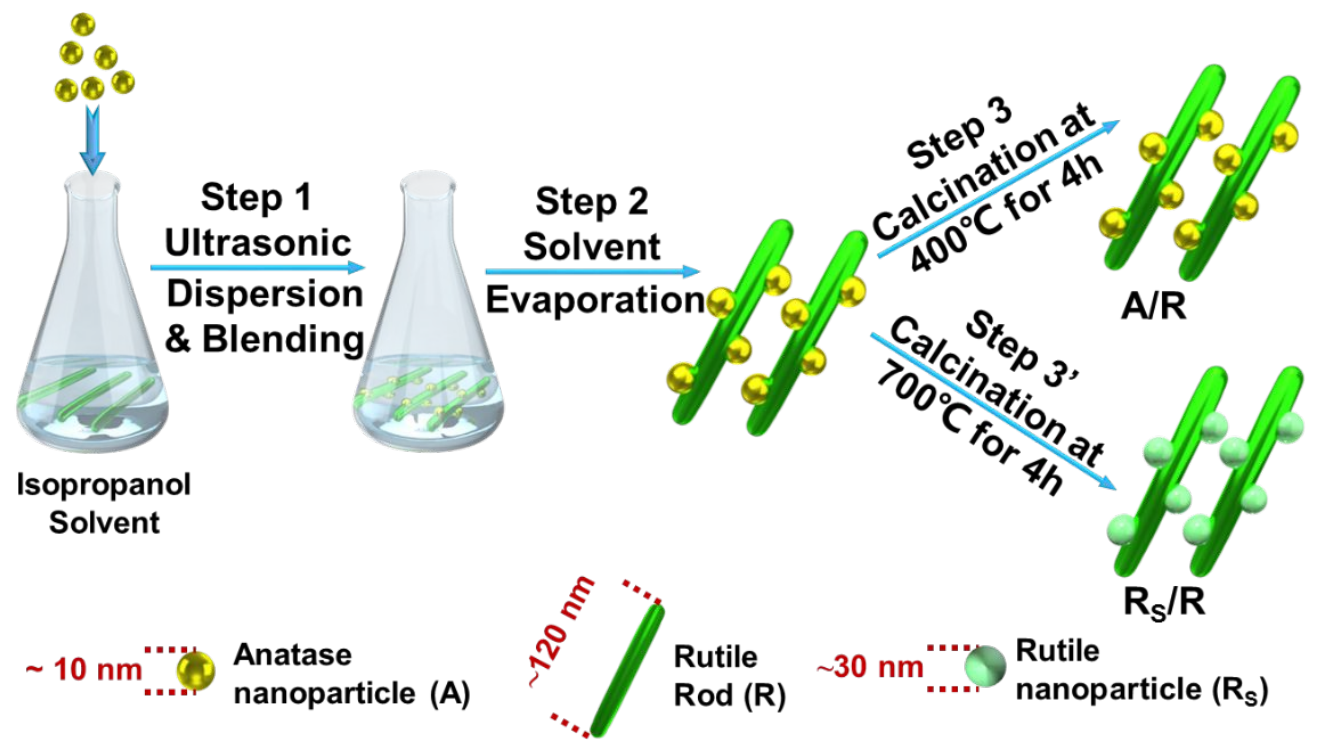

Scheme S1. Schematic illustration of preparing $A / R$ heterophase junction and $R_{s} / R$ homophase junction. 

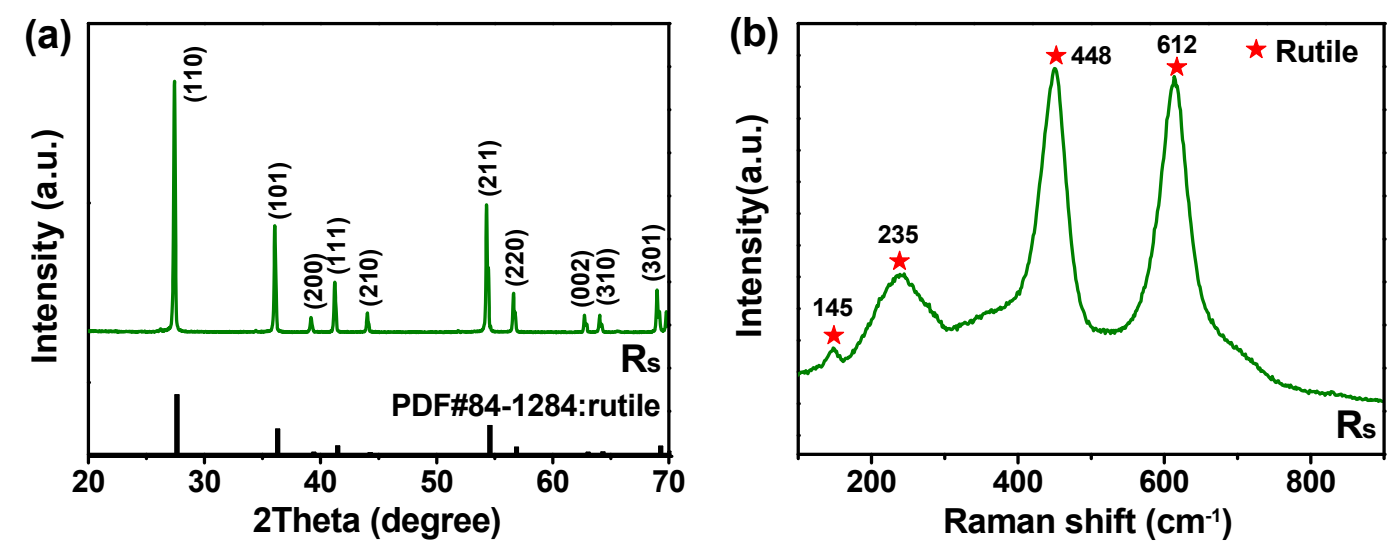

Figure S3. (a) XRD pattern and (b) Raman spectrum of $\mathrm{R}_{\mathrm{s}}$ sample. 

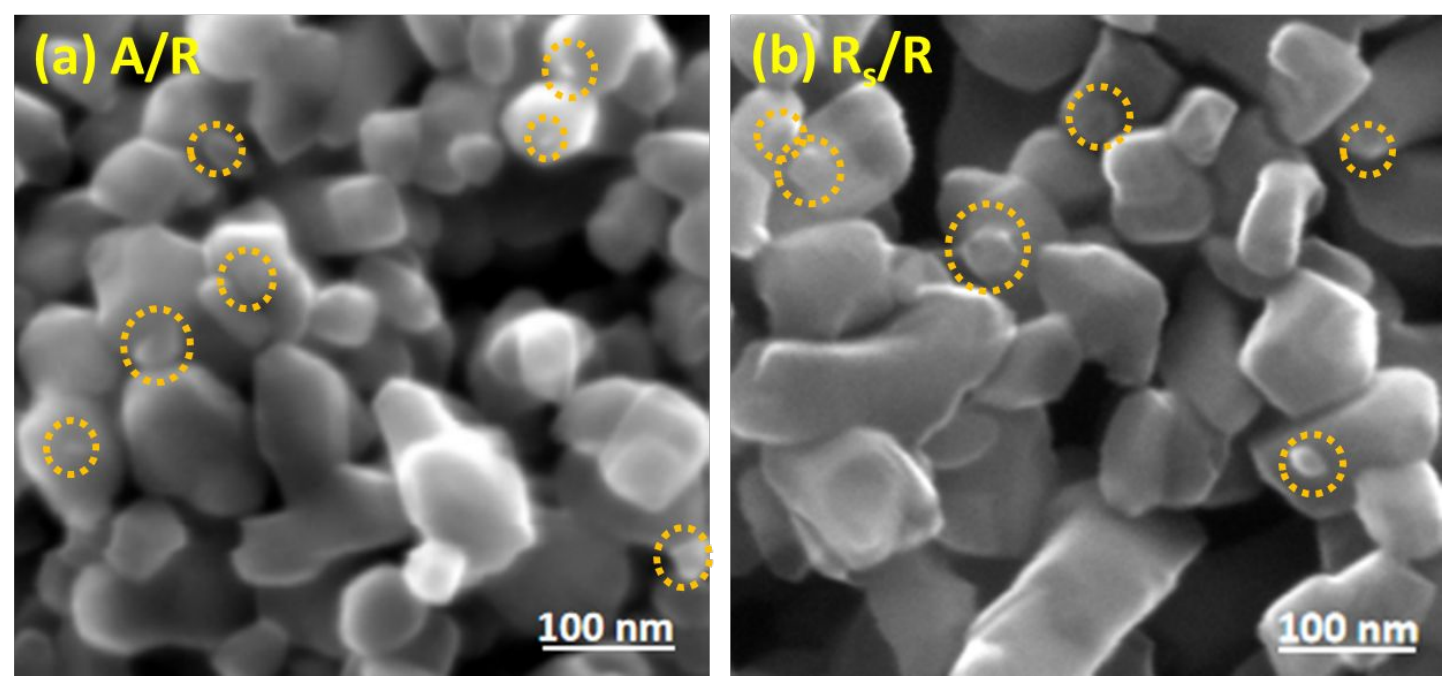

Figure S4. SEM images of (a) $A / R$ and (b) $R_{s} / R$ samples. 
Table S1. BET surface areas of $R, A / R$ and $R_{s} / R$ samples.

\begin{tabular}{cccc} 
Sample & BET $\left(\mathrm{m}^{2} / \mathrm{g}\right)$ & Sample & BET $\left(\mathrm{m}^{2} / \mathrm{g}\right)$ \\
$\mathbf{1 \%} \mathbf{A} / \mathbf{R}$ & 40 & $\mathbf{R}$ & 15 \\
\hline $\mathbf{5 \%}$ A $/ \mathbf{R}$ & 42 & $1 \% \mathbf{R}_{\mathbf{s}} / \mathbf{R}$ & 16 \\
\hline $10 \%$ A $/ \mathbf{R}$ & 43 & $5 \% \mathbf{R}_{\mathbf{s}} / \mathbf{R}$ & 17 \\
\hline & & $10 \% \mathbf{R}_{\mathbf{s}} / \mathbf{R}$ & 18 \\
\hline
\end{tabular}




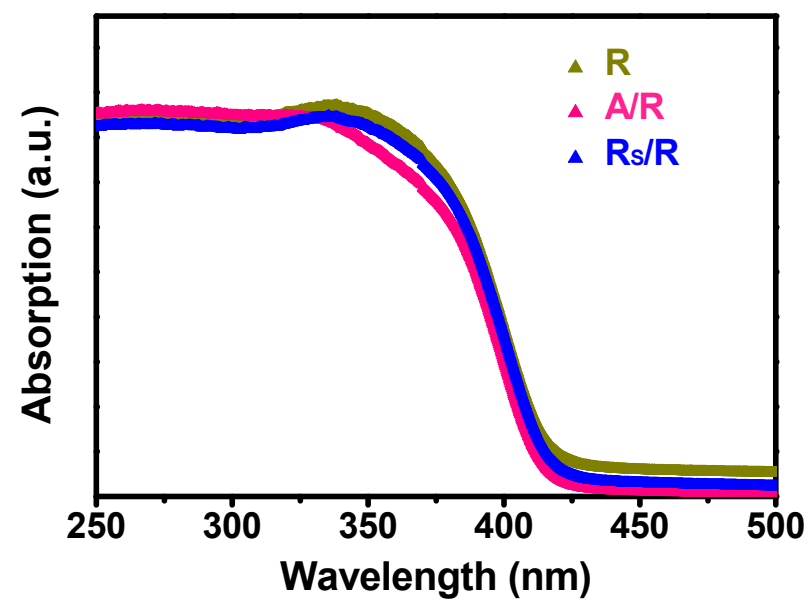

Figure S5. UV-vis diffuse reflectance spectra of R, 5\% A/R, and 5\% $\mathrm{R}_{s} / \mathrm{R}$. 


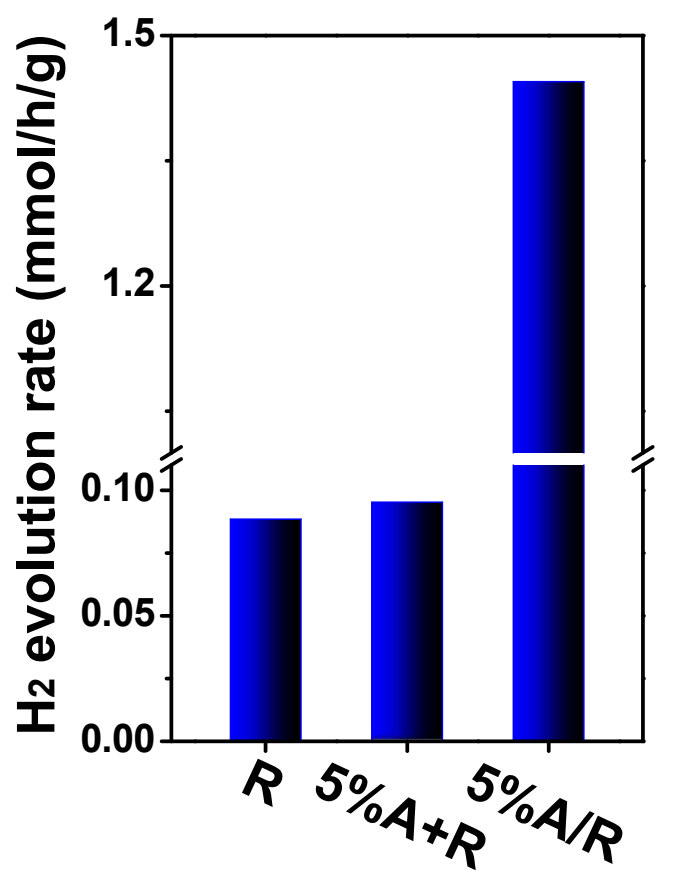

Figure S6. The overall photocatalytic $\mathrm{H}_{2}$ evolution on $\mathrm{R}, 5 \% \mathrm{~A}+\mathrm{R}$, and $5 \% \mathrm{~A} / \mathrm{R}$ samples with methanol as scavenger, $0.2 \mathrm{wt} \% \mathrm{Pt}$ photodeposited as cocatalyst and xenon lamp (300 W) used as light source. 


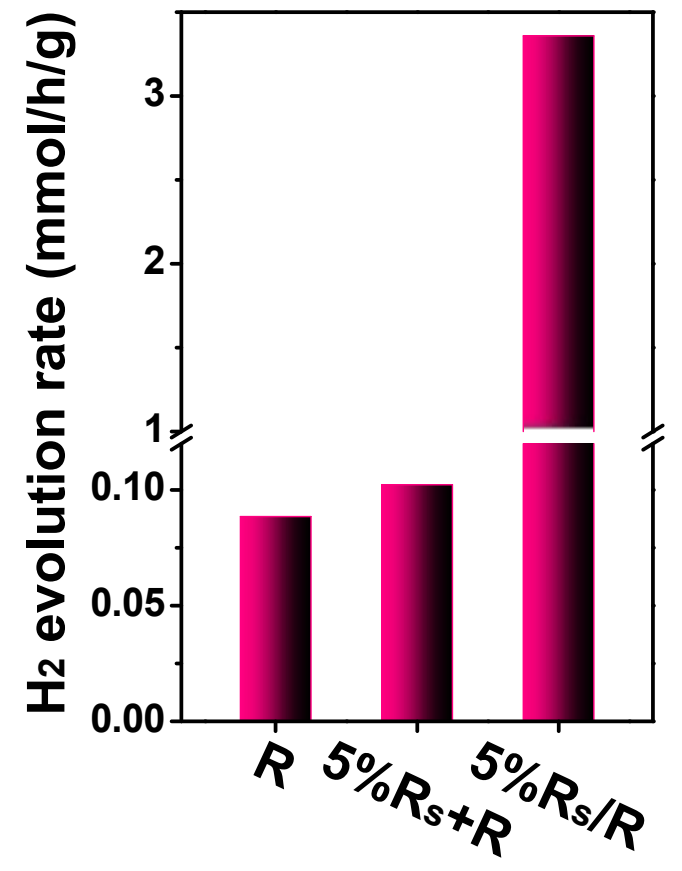

Figure S7. The overall photocatalytic $\mathrm{H}_{2}$ evolution on $\mathrm{R}, 5 \% \mathrm{R}_{\mathrm{s}}+\mathrm{R}$, and $5 \% \mathrm{R}_{\mathrm{s}} / \mathrm{R}$ samples with methanol as scavenger, $0.2 \mathrm{wt} \%$ Pt photodeposited as cocatalyst and xenon lamp $(300 \mathrm{~W})$ used as light source. 


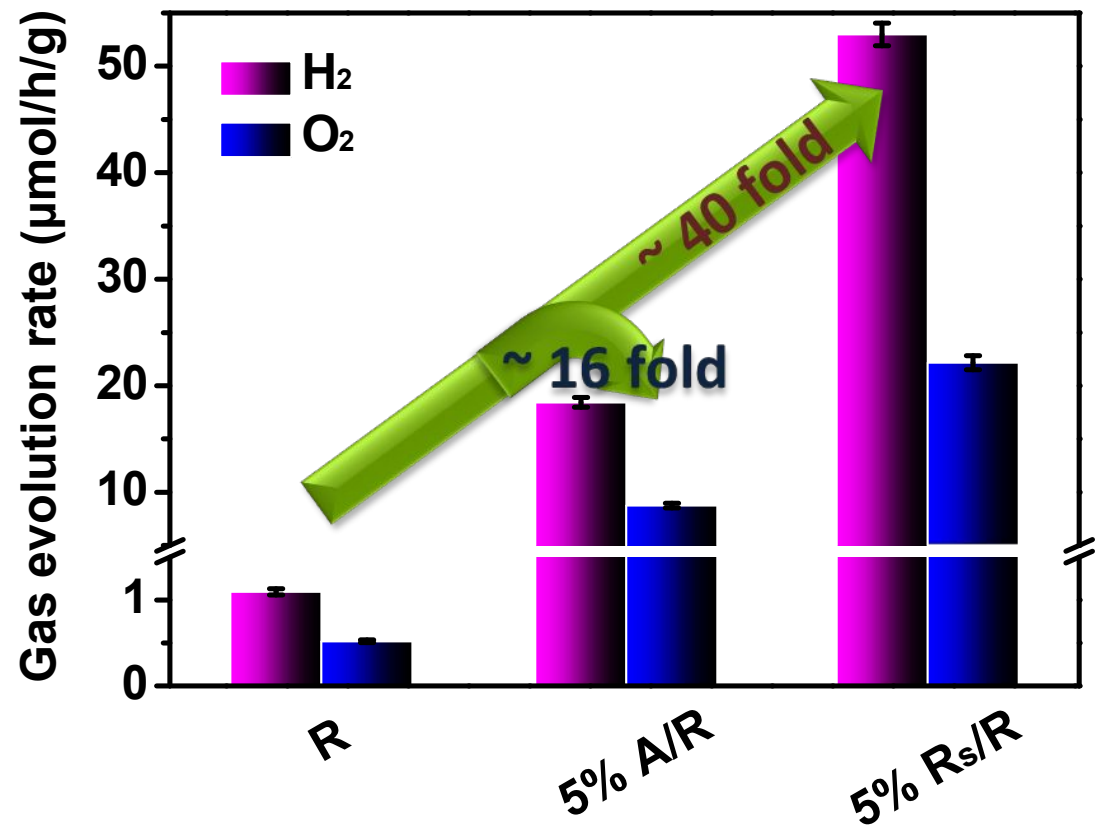

Figure S8. Comparison of photocatalytic overall water splitting performance on R, $5 \% \mathrm{~A} / \mathrm{R}$, and $5 \% \mathrm{R}_{\mathrm{s}} / \mathrm{R}$ samples. 


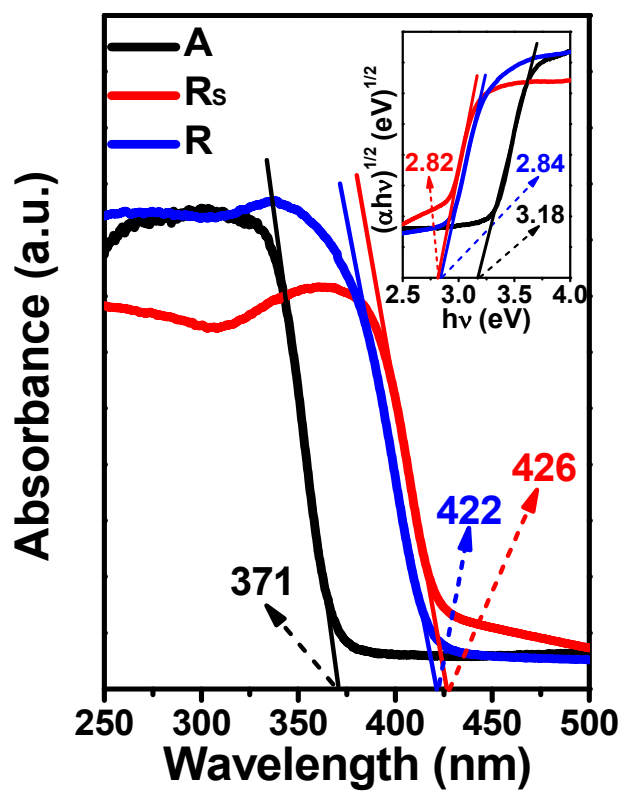

Figure S9. UV-vis diffuse reflectance spectra (inset: the estimated band gap of A, $\mathrm{R}_{\mathrm{s}}$, and $\left.\mathrm{R}\right)$. 
(a)

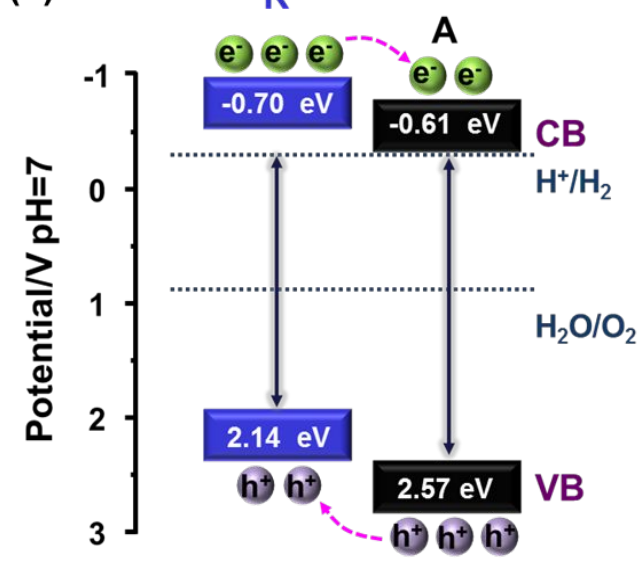

(b)

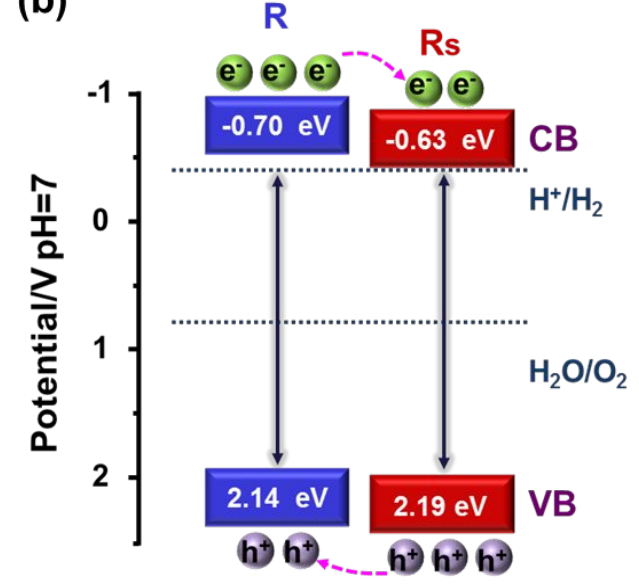

Figure S10. Schematic illustration of the band structures of (a) A and R, (b) $R_{s}$ and R. 


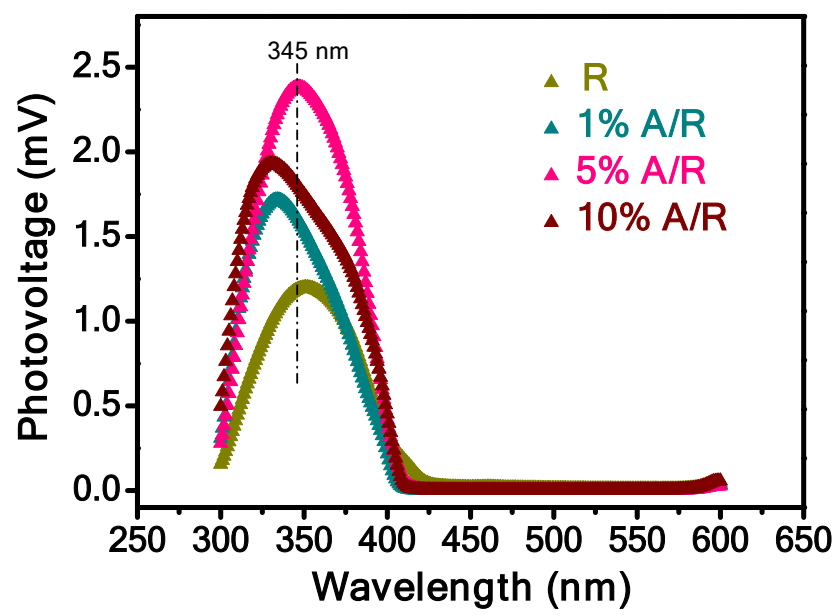

Figure S11. SPV responses of R and A/R samples. 